\title{
Prevalence of dengue viral infection (DI) in and around of Angul district of Odisha, India: A comprehensive eco-epidemiological study.
}

\author{
M. Rajesh Kumar Rao ${ }^{1}$, R. N. Padhy ${ }^{2}$ \\ ${ }^{I}$ Department of Biotechnology, Sai Nath University, Ranchi, Jharkhand. \\ ${ }^{2}$ Central Research Laboratory, Institute of Medical Sciences \& Sum Hospital, S'O'A University, K-8, Kalinga \\ Nagar, Bhubaneswar-751003, Odisha, India.
}

\begin{abstract}
Currently, the disease 'dengue viral infection (DI)' was endemic in Angul district, Odisha state, as the region fall in the deciduous, dry and wet climatic zone. This study was designed to analyze a relationship of DI with climatic factors (rainfall, temperature and relative humidity) during the year, 2013. During the study, monthly climatologically data was obtained and analyzed; and 1980 blood specimens of dengue suspected cases were collected and diagnosed. Out of 1980 suspected cases, 745 cases (37.6\%) were confirmed as DI. Larger proportions of DI were observed among adults. The difference between DI positive cases during different months was significant $(p<0.05)$. DI coincided mainly with the monsoon period of heavy rainfall. The difference between DI positive cases as compared to DI negative in monsoon period was significantly higher $(p<0.001)$. This prospective study highlighted rain, temperature and relative humidity as the major and important climatic factors, which could alone or collectively be responsible for the epidemic or outbreak. More studies in this regard could further reveal the correlation between the climatic changes and epidemics or outbreaks, which would help in making the strategies to forecast any epidemic or outbreak in the future well in advance.
\end{abstract}

Keywords: Dengue Infection, Dengue fever, Rainfall, Temperature, Relative humidity.

\section{Introduction}

Dengue infection (DI) is amongst the most important emerging viral diseases transmitted by mosquitoes to humans, in terms of both illness and death [1]. In the tropics and subtropics, infections from the dengue virus (DENV) are transmitted by the vectors of Aedes species. The Dengue virus (DENV), a mosquitoborne member of the family 'Flaviviridae', circulates as four distinct serological types DENV-1, DENV-2, DENV-3, and DENV-4 [2-4]. These four serotypes offer cross protection for a very short period. Infection with any of these leads to a mild self-limiting febrile illness (dengue fever, DF). Although all the four serotypes have been circulating in this region, ecological and climatic factors are reported to influence the seasonal prevalence of the dengue vector, Aedes aegypti, on the basis of which, countries in this region are divided into four zones with different DF/DHF transmission potential [5].

The worldwide large-scale reappearance of dengue for the past few decades has turned this disease into a serious public health problem and also the dengue fever (DF) has gradually become one of the leading causes of morbidity and mortality in tropical and subtropical areas throughout the world [6]. Overall, two-fifth of the world population is living in areas, at risk for dengue [7-9]. It is estimated that $52 \%$ of the global population are at the risk of contracting Dengue fever (DF) or dengue hemorrhagic fever (DHF) lives in the South East Asian Region (SEAR). In most of the countries, dengue epidemics are reported to occur, during the warm, humid and rainy seasons, which favor the abundant mosquito growth and shorten the extrinsic incubation period as well [10-13].

DF has been known to be endemic in India for over two centuries as a benign and self-limited disease. In recent years, the disease has changed its course manifesting in the severe form of the disease, dengue hemorrhagic fever/dengue shock syndrome (DHF/DSS), is responsible for high mortality rate, especially in children [14]. It has been estimated that about 50 million cases of DF occur annually, with 10,000 infant deaths due to DHF/DSS. DHF/DSS has been postulated to result from immune enhancement after a second heterologous DENV infection [15]. In India, DENV was first isolated in 1946 and many outbreaks have been reported [16-19]. DF was first reported in Calcutta, West Bengal in 1963 [20]. Overpopulation has consequently led to poor sanitary conditions and water logging at various places. A major epidemic of DHF from Delhi was last reported in the year 1996 after which DI became a notifiable disease and a number of policies were formulated to bring the DI as well as its vector under control [21-22].

Particularly, Odisha state is considered as endemic for dengue fevers. In the state, DENV infection was first documented in 1998; and several epidemics due to DENV precipitated after 2005, causing an increase of 
the case fatality rate (CFR =total mortality X100/total positive cases of dengue) [23]. In the year 2011, Odisha in India had experienced one of the wettest monsoons in 25 years, which led to a spate of mosquito growth creating an alarming situation of mosquito borne diseases in many districts. For an instance in 2011, of the total 1846 detected dengue cases in Odisha, 33 death cases occurred with the epicenter at the Talcher coalmine area of Angul district; the maximum number of dengue positive cases (33.7\%), with the CFR at $66.7 \%$ had been reported alone in the Angul district [23]. In the rural, semi-urban and urban areas of Angul district, the vectors Aedes occur throughout the year [23]. There are numerous scientific reports on investigation of dengue fever (DF) and dengue haemorrhagic fever (DHF), from various parts of the Indian subcontinent [24-29] and studies conducted in the countries like Brazil, Indonesia and Venezuela, where DI is present either in epidemic or endemic form have suggested a correlation between the weather and the pattern of DI. Rain, temperature and relative humidity are suggested as important factors attributing towards the growth and dispersion of this vector and potential of dengue epidemic or outbreaks [30-32].

However, systematic studies on the association of climatic conditions and the pattern of DI from this geographical region in Angul district of Odisha, India has yet not been attempted, either in epidemic or in sporadic dengue outbreaks in Odisha, Indeed, except recording of prevalence/ epidemiological trends of both diseases in databases, there is no systematic study [23].

Therefore, the study was conducted to find out the relationship of dengue infection (DI) with climatic factors such as the rainfall, temperature and relative humidity during January to December, 2013 in Angul district of Odisha, India. This paper presents a comprehensive surveillance report on the correlation between dengue infection with climatic factors such as the rainfall, temperature and relative humidity in the Angul district of Odisha and also to mapping the prevalence of dengue infection presently conquered in this region.

\section{Materials And Methods}

The present study was conducted retrospectively for a period of one year during January to December, 2013 in Angul district of Odisha, India. The study population comprised individuals of all age groups.

\subsection{Study area:}

Centrally located Angul district with area $6232 \mathrm{sq} . \mathrm{km}\left(20^{\circ} 31^{\prime} \mathrm{N}\right.$ and $21^{\circ} 40^{\prime} \mathrm{N}$ latitude and $84^{\circ} 15^{\prime} \mathrm{E}$ and $85^{\circ} 23^{\prime}$ E longitude) in the state of Odisha has the total population of 1,271,703 with males 654,898 and females 616,805 , as per 2011-census. With a brief winter, the climate of the district is sub-tropical with the temperature range, 6 to $47^{\circ} \mathrm{C}$ (Figure 1).

\subsection{Clinical Specimens:}

Dengue suspected cases in accordance with the observation of non-specific constitutional symptoms were collected by the passive case detection (PCD) method from the study area of Angul district, Odisha during January to December, 2013. For the selection of DF cases in 3 phases, febrile phase, critical phase and recovery phase, the following criteria were considered: (a) high fever, (b) headache, (c) retro-orbital pain, (d) nausea/vomiting, (e) myalgia (muscle pain), (f) generalized skin rashes, (g) athralzia, (h) diarrhea, (i) fatigue, (j) pleural effusion, (k) hypotension, (l) ascites; (m) gastrointestinal bleeding in critical phase, (n) itching, (o) slow heart rate, (p) seizures and (q) altered level of consciousness [23]. In case of DHF, the history of illness was revealed by the sudden rise of fever $\left(38.3-39.4^{\circ} \mathrm{C}\right)$, headache, retro-orbital pain, conjunctival congestion, and facial flashing with fever sustaining for 2-15 days. Additionally, some cases had the history of hemorrhagic manifestation either with petechiae or with gum bleeding or haematuria or melena.

Clinical specimens (blood samples) of all febrile cases were collected for the diagnosis of DENV infections. A total of 1980 blood samples was received from the suspected cases and transported on dry ice for analysis. Sera separated from the collected blood samples were stored at $-80^{\circ} \mathrm{C}$ and were tested within 1 month.

\subsection{Diagnosis:}

The 1980 blood samples, dengue suspected cases were analyzed in the laboratory by (a) rapid diagnostic test (RDT) method, (b) enzyme-linked immunosorbent assay (ELISA) method, and (c) molecular method for the detection of dengue infection using polymerase chain reaction (PCR) method the confirmation of the dengue infection (DI) in a patient. But the positive (reactive) result of dengue infection for anti-dengue NS1Ag ELISA method was equivalent to a value above the cut-off point for dengue.

\subsubsection{Laboratory confirmation of dengue infection:}

The diagnosis of DI was made by detection of IgM/ IgG antibody and NS-1 antigen in blood by RDT using the 'Advantage Dengue NS1 Ag and Ab Combi card' ( $\mathrm{J}$ Mitra and Co, New Delhi), following the prescribed protocol [33]. All the samples were screened for the presence of dengue IgM antibodies by IgM capture ELISA, using a kit (J Mitra and Co.), following the prescribed protocol [34]. Optical density was 
measured at $450 \mathrm{~nm}$ in the ELISA reader (Titertek Multiskan Plus, Finland, type-314). Reverse transcriptasepolymerase chain reaction (RT-PCR) was the method was done in the first 5 days of fever onset; the presence of the virus was done by RT-PCR in all serum samples collected during the acute phase of infection, between day 0 and day 4 of fever occurrence [35].

\subsection{Analysis of metrological data:}

Monthly details of total rainfall, temperature and relative humidity for all the months of the year, 2013 were obtained from the 'Meteorological Department of Angul district, Odisha' and retrospectively analyzed in relation to the total number of dengue infection positive cases. According to the intensity of the rainfall, weather data was divided into three periods, namely; pre-monsoon period: from February- May, monsoon period: from June - September and post monsoon period: from October - January.

\subsection{Analysis of data:}

During the study (January to December, 2013), the statistical data's of the prevalence of dengue infection with climatic factors such as the rainfall, temperature and relative humidity were entered in Excel format by given codes as per the requirement and the data was analyzed by using the computer program Excel2003 to find out the co-relation of dengue infection with the three important climatic factors such as rainfall, temperature and relative humidity in comparison to $p$ value $(\mathrm{p}<0.05$ and $\mathrm{p}<0.001)$. The statistics were used in this study as the following: percentage (\%), mean and standard deviation (SD). The statistics graph was designed by the chart wizard in this study as the following: lines chart wizard and line column in 2 axes chart wizard.

\section{Results.}

3. Distributions of prevalence of dengue viral infection (DI).

During the study (January to December 2013), a total of 1980 blood samples (dengue-like illness suspected cases) was examined in confirming dengue infection cases. The positive (reactive) result for antidengue NS1Ag ELISA method was equivalent to a value above the cut-off point for confirmation of dengue infection. Out of the 1980 blood specimens diagnosed, dengue infection was diagnosed in 745 (37.6\%). Of $745(37.6 \%)$ cases, $715(96.0 \%)$ cases were detected dengue primary (DEN-P) infection (having IgM antibodies only) and $30(4.0 \%)$ cases were detected as dengue secondary (DEN-S) infection (having both IgM and IgG antibodies). The result was shown that, the dengue primary infection was more prevalent than the dengue secondary infection. The difference between numbers of serologically positive cases reported during different months was significant $(\mathrm{p}<0.05)$.

\subsection{Distribution by age groups and sex wise:}

During the study, it was observed that, in infants up to one year age, there were no positive cases of DENV infection, but of 16 blood samples of children of $>1-5$ year age examined, there was a single case of DENV infection. Similarly, in children from $>5-10$ year age, there were 9 DENV infection positive cases of 49 samples, but in the adult age group, i.e., >15 year and above, there were 707 confirmed cases of DENV infection using ELISA; nonetheless, a negligible variance in RDT and PCR values were presented (Table 1).

The distributions of the prevalence of dengue infection were presented (Table 2). The confirmed cases of dengue infection were significantly more in males $(545,73.3 \%)$ rather than females $(200,26.7 \%)$ during the study period. Out of those total suspected cases, the highest confirmed cases of dengue was found in the age group of $>15$ year \& above $(707,94.9 \%)$; whereas, the lowest confirmed cases of dengue in the age group of $>1-5$ year $(1,0.1 \%)$ followed by the age group $>5-10$ year $(9,1.2 \%)$. The mean value was noted in male (109.0) and female (40.0) respectively; whereas, the highest case positivity rate (CPR) was recorded in the age group of $>15$ year and above $(39.2 \%)$ followed by $>10-15$ year $(25.2 \%)$ and lowest in $>1-5$ year $(6.3 \%)$ followed by $>5-10$ year $(18.4 \%)$. Out of those total dengue positive cases, no death case was noted and the case fatality rate (CFR) was $0.0 \%$; and no incidence was detected in the age group of 0 to 1year during the study.

The results of the distributions (Sex and age groups wisely) of the prevalence of dengue infection (primary \& secondary) cases were presented (Table 3). The results revealed that, the dengue primary (DEN-P) infection was found significantly more in males $(534,71.7 \%)$ in comparison to females $(181,24.3 \%)$. The dengue primary infection was also found significantly prevalent in males than in females among all age groups. The highest primary dengue infection was detected in the age group of $>15$ year and above $(678,91.0 \%)$ followed by $>10-15$ year $(27,3.7 \%)$ and lowest in $>1-5$ year $(1,0.1 \%)$ followed by $>5-10$ year $(9,1.2 \%)$. The mean value of dengue primary infection was recorded $(143.0,19.2 \%)$ among sex and age group wise respectively. Similarly, the dengue secondary (DEN-P) infection was found significantly more in females $(19,2.6 \%)$ in comparison to males $(11,1.4 \%)$. The dengue secondary infection was found prevalent among males \& females; the difference was not statistically significant among all age groups. The highest secondary 
dengue infection was observed in the age group of $>15$ year and above $(29,3.9 \%)$ and lowest in $>5-10$ year $(1,0.1 \%)$. The mean value of dengue secondary infection was recorded $(6.0,6.8 \%)$ among sex and age group wise respectively. Still, no dengue positive case was found in the age group of 0 to 1 year and the dengue secondary infection was not detected both males and females in the age group of 0 to 10 year during the study.

\subsection{Distribution by month wise:}

Dengue infection (DI) is observed to be a seasonal disease in Angul district, Odisha. According to the intensity of rainfall, weather data was divided into three periods, namely; pre monsoon period: from FebruaryMay, monsoon period: from June - September and post monsoon period: from October - January. Month-wise distributions of the prevalence of dengue infection were also presented (Figure 2). It was seen that, dengue like illness suspected cases in the pre monsoon period were found to be negative for dengue infection. During the post monsoon period, only 166 cases $(22.3 \%)$ were confirmed serologically positive in the month of October, $17(2.3 \%)$ cases in the November and 2 cases $(0.3 \%)$ in the December. Dengue infection positive cases were mainly detected during the monsoon period with maximum number of cases $318(42.7 \%)$ cases reported during the month of September followed by 215 (28.9\%) cases in the August and 27 (3.6\%) cases in July. The difference between numbers of DI positive cases as compared to DI negative ones in monsoon period was significantly higher $(\mathrm{p}<0.001)$, than during the remaining period with $55 \%$ of total annual cases reported during this period. The highest case positivity rate (CPR) was observed during the monsoon period in the month of September 318 (57.9\%) followed by 215 (47.7\%) in August; whereas, the lowest CPR was observed during the post monsoon period in the month of December 2 (6.5\%) followed by 17 (8.9\%) in the November. Howe ver, in months, January to June, 2013 no dengue positive case was detected in this study area of Angul district, Odisha.

Month-wise distributions of the prevalence of dengue infection (primary \& secondary) were also presented (Table 4 and Figure 3). It was seen that, the highest dengue primary infection was observed during the monsoon period in the month of September (305, 40.9\%) followed by August (207, 27.8\%); whereas, lowest dengue primary infection was observed during the post monsoon period in the month of December $(2,0.3 \%)$ followed by $15(2.0 \%)$ in the November. Similarly, the highest dengue secondary infection was observed during the monsoon period in the month of September $(13,1.7 \%)$ followed by August $(8,1.1 \%)$, whereas, the lowest dengue secondary infection was observed during the post monsoon period followed by July $(1,0.1 \%)$. The difference between numbers of dengue primary infection as compared to dengue secondary infection in monsoon period was significantly higher $(\mathrm{p}<0.001)$, than during the remaining period with total annual cases reported during this period. However, during the pre-monsoon no dengue infection (primary \& secondary) was detected in this study area of Angul district, Odisha.

\subsection{Climatic influence:}

The climatologically status of 2013 in the Angul district of Odisha, India was presented (Table 5). It was observed that, the annual rainfall of the district was recorded as $1304 \mathrm{~mm}$ and the average annual rainfall was $108.7 \mathrm{~mm}$. The highest rainfall was recorded $(354.6 \mathrm{~mm})$ in the month of September; whereas, the lowest rainfall was $(5.4 \mathrm{~mm})$ in the month of November \& December. May was the hottest month with a mean daily maximum temperature of 46 degree Celsius. With the onset of monsoon, early in the month of June the day temperature drops appreciably. December was usually the coldest month of the year with a mean daily minimum temperature of $14^{\circ}$ Celsius. The highest maximum temperature was recorded in Angul district ( $46^{\circ}$ Celsius) in the month of May; whereas, the lowest minimum temperature was recorded $\left(13^{\circ}\right.$ Celsius) in the month of January. The humidity of the air was generally high and the high humidity was recorded (90\%) in the month of July, especially during the South West monsoon and post monsoon months; whereas, the lowest humidity was $60 \%$ in the month of January. The afternoons were comparatively drier throughout the year, the relative humidity varies between 62 to 90 percent and the average annual humidity was recorded $74.7 \%$.

Month wise distributions of the prevalence of dengue infection and climatologically (rainfall, temperature and relative humidity) condition in Angul district, Odisha during January to December, 2013 were presented (Figure 4, 5 and 6). The result indicates that, the dengue viral infection (DI) coincided mainly with the monsoon period of heavy rainfall (Cumulative rainfall $=266.7 \mathrm{~mm}$ ) from June to September 2013 and was followed by relatively subnormal rainfall (Cumulative rainfall $=25.9 \mathrm{~mm}$ ) during the post monsoon period; from October to December 2013. The divergence in the rainfall and temperature between three seasonal periods was found to be important ( $\mathrm{p}<0.05$ ) (Figure 4 and 5). The mean ambient temperature was $32.5^{\circ} \mathrm{C}$ during the pre monsoon period, which fell to $29.8^{\circ} \mathrm{C}$ during the monsoon period; the period preceding the highest prevalence of dengue infection, which leads to dengue epidemic or outbreak and decreased to $23.9^{\circ} \mathrm{C}$ during the post monsoon period; the period preceding the prevalence of dengue infection gradually starts decreasing. The difference between relative humidity during the three periods was not significant. The mean relative humidity was $74.3 \%$ during the pre monsoon period. It increased during the monsoon period to $82.8 \%$ and decreased during the post monsoon period to $67.0 \%$ (Figure 6). 


\section{Discussion}

Currently, the disease 'dengue viral infection (DI)' was endemic in all continents except Europe. In India, DENV was first isolated in 1946 and many outbreaks have been reported [16-19]. DI was first reported in Calcutta, West Bengal in 1963 and the first dengue outbreak occurred in Calcutta, India in 1963 with 30\% DHF cases [20]. Particularly, Odisha state was considered as endemic for dengue infection. In the state, DENV infection was first documented in 1998; and several epidemics due to DENV precipitated after 2005, causing an increment of the case fatality rate (CFR) [23]. In the year 2011, Odisha in India had experienced one of the wettest monsoons in 25 years, which led to a spate of mosquito growth creating an alarming situation of mosquito borne diseases in many districts. There are numerous scientific reports on investigation of dengue fever (DF) and dengue haemorrhagic fever (DHF), from various parts of the Indian subcontinent [24-29] and studies conducted in the countries like Brazil, Indonesia and Venezuela, where DI is present either in epidemic or endemic form have suggested a correlation between the weather and the pattern of DI. Rain, temperature and relative humidity are suggested as important factors attributing towards the growth and dispersion of this vector and potential of dengue epidemic or outbreaks [30-32]. Most of vector borne diseases exhibit a distinctive seasonal pattern and climatic factors such as rainfall, temperature and other weather variables affect in many ways both the vector and the pathogen they transmit [36]. Worldwide studies have proposed that ecological and climatic factors influence the seasonal prevalence of both the Ae. aegypti and dengue virus. In the rural, semiurban and urban areas of Angul district, the vectors Aedes occur throughout the year [23]. The vector mainly responsible for the spread of DI is present at the basal level all the year around in Angul district of Odisha, However, systematic studies on the association of climatic conditions and the pattern of DI from this geographical region in Angul district of Odisha, India has yet not been attempted, either in epidemic or in sporadic dengue outbreaks in Odisha, Indeed, except recording of prevalence/ epidemiological trends of both diseases in databases, there is no systematic study [23]. This study was planned to carry out the month wise detailed analysis the relationship of dengue infection with the three important climatic factors such as rainfall, temperature and relative humidity on the pattern of DI in Angul district of Odisha, India.

Observations on the seasonality were based on a single year's data. The result indicates that, the dengue viral infection (DI) coincided mainly with the monsoon period of heavy rainfall from June to September 2013 and was followed by relatively subnormal rainfall during the post monsoon period; from October to December 2013. The divergence in the rainfall and temperature between three seasonal periods was found to be important $(\mathrm{p}<0.05)$. Monthly weather data showed that temperature variations were more amongst different months during the pre monsoon and post monsoon period as compared to the monsoon period. Even though, the monsoon season began in mid- June, there was no respite from the heat as there was not much difference in the temperature during the last month of pre monsoon; May and beginning of monsoon in the June. Unusually heavy rainfall subsequently led to decrease in temperature during the later part of monsoon period. The temperature showed a decline during the months of July and August, continuous heavy rainfall subsequently led to a further decrease in the temperature during the month of September to $34^{\circ} \mathrm{C}$. The mean ambient temperature was $32.5^{\circ} \mathrm{C}$ during the pre monsoon period, which fell to $29.8^{\circ} \mathrm{C}$ during the monsoon period; and further decreased to $23.9^{\circ} \mathrm{C}$ during the post monsoon period. Relative humidity increased during the rainy season and remained high for several weeks. The difference between relative humidity during the three periods was not significant. The mean relative humidity was $74.3 \%$ during the pre monsoon period. It increased during the monsoon period to $82.8 \%$ and decreased during the post monsoon period to $67.0 \%$. An in-depth analysis of these three factors, thus led to a proposal that optimum temperature with high relative humidity and abundant stocks of fresh water reservoirs generated due to rain developed optimum conditions conducive for mass breeding and propagation of vector and transmission of the virus. This study supported the proposal that all the three climatic factors studied could be playing an important role in creating the contributing condition required for breeding and propagation of this vector, the basal level of which is present all round the year. This prospective study was therefore highlighted the major important factors, which could alone or collectively be responsible for an epidemic or outbreak.

In our study, the largest proportion of dengue viral infection positive cases were recorded in the monsoon period, but the results of the seasonal occurrence of positive cases in Bangladesh has shown significantly different that post monsoon period was the most affected period [37]. However, a retrospective study from Myanmar during 1996-2001 reported the maximum cases of dengue during the monsoon period [38]. Study of a group of Rebelo from Brazil has also emphasized the importance of the season. They have observed that dengue cases were higher during the rainy season showing the importance of rain in forming prime breeding sites for Ae. aegypti thus spread of DI [39]. Study of eco-epidemiological factors, by Barrera et al [39] showed that DI has a positive correlation with the relative humidity and negative relation with evaporation rate. Peaks of dengue cases were observed to be near concurrent with rain peaks in this study from Venezuela showing a significant correlation of intensity of DI with the amount of rain [40]. In this study, we have observed that temperature tends to decrease towards the end of monsoon period, specially remains 
Prevalence of dengue viral infection (DI) in and around of Angul district of Odisha, India: ...

moreover constant during the later months of rainy season. Angul district of Odisha, India fall in the deciduous, dry and wet climatic zone. The temperature remains high during the pre monsoon period. It is continuous rain pouring for a couple of days that brings down the temperature during the monsoon period, which may also be responsible for an increase in the relative humidity and decrease in the evaporation rate thus maintaining secondary reservoirs containing rain water. More studies are needed to establish the relationship between the climatic changes and dengue outbreaks, which would help in formulating the strategies and plans to forecast any epidemic or outbreak in the future, well in advance.

Very little dengue is found in adults in Thailand, presumably because people acquire complete protective immunity after multiple DI as children [1], as DI is highly endemic in Thailand [41]. On the other hand, DI especially is an emerging disease in Odisha, India; probably this may be the reason that people of all the age are found to be sensitive to infection in our study. Even though more adults were reported of having anti dengue antibodies, infants and youngsters were not infected by any of the pathogens nor did adults have any sex-based differentiation in infection. The difference in the number of positive cases was not significant as compared to pediatric age group.

During the study (January to December, 2013), it was studied \& analysis the relationship of dengue infection with the three important climatic factors such as rainfall, temperature and relative humidity on the pattern of dengue infection (DI) in Angul district of Odisha, India and the outcome of the study is good and satisfactory.

\section{Conclusion}

This prospective study highlighted rain, temperature and relative humidity as the major and important climatic factors, which could alone or collectively be responsible for an epidemic or outbreak. More studies in this regard could further reveal the correlation between the climatic changes and dengue endemic, epidemic or outbreaks, which would help in making the strategies and plans to forecast any endemic, epidemic or outbreak in the future well in advance and also early diagnosis and treatment with drugs were possible to control the prevalence of the dengue infection.

\section{Acknowledgements}

This work is a part of the Ph.D thesis in Biotechnology. R.N. Padhy is a CSIR Scientist. My sincere thanks to all the population of Angul district, odisha, for their cooperation.

\section{References}

[1]. Gubler DJ: Dengue and dengue hemorrhagic fever. Clin Microbiol Rev 1998, 113:480-496.

[2]. W. J. H. McBride and H. Bielefeldt-Ohmann, "Dengue viral infections; pathogenesis and epidemiology," Microbes and Infection, vol. 2, no. 9, pp. 1041-1050, 2000.

[3]. E. A. Henchal and J. R. Putnak, "The Dengue viruses,” Clinical Microbiology Reviews, vol. 3, no. 4, pp. 376-396, 1990.

[4]. T. Solomon and M. Mallewa, "Dengue and other emerging flaviviruses," Journal of Infection, vol. 42, no. 2, pp. 104-115, 2001.

[5]. WHO: Health Situation in the South East Asian Region 1998-2000. WHO Regional Office, South East Asia, New Delhi.

[6]. Kyle JL, Harris E. Global spread and persistence of dengue. Annu Rev Microbiol 2008, 62:71-92.

[7]. Bhatt S, Gething PW, Brady OJ, Messina JP, Farlow AW, Moyes CL, Drake JM, Brownstein JS, Hoen AG, Sankoh O, et al. The global distribution and burden of dengue. Nature 2012, 496:504- 507.

[8]. Guzman MG, Halstead SB, Artsob H, Buchy P, Farrar J, Gubler DJ, Hunsperger E, Kroeger A, Margolis HS, Martinez E, et al. Dengue: a continuing global threat. Nat Rev Microbiol 2010, 8:S7-S16.

[9]. World Health Organization, "Dengue and Dengue haemorrhagic fever," Fact sheet, pp. 117, 1996.

[10]. Gibbons RV, Vaughn DW: Dengue: an escalating problem. BMJ 2002, 324:1563-1566. PubMed Abstract | Publisher Full Text

[11]. Innis BL: Dengue and dengue hemorrhagic fever. In Kass handbook of infectious diseases: exotic virus infections. Edited by Porterfield JS. London: Chapman and Hall Medical; 1995:103-146.

[12]. Rigau-Perez JG, Clark GG, Gubler DJ, Reiter P, Sanders EJ, Vorndam AV: Dengue and dengue hemorrhagic fever. Lancet 1998, 352:971-977. PubMed Abstract | Publisher Full Text.

[13]. McBride WJ, Bielefeldt-Ohmann H: Dengue viral infections: pathogenesis and epidemiology. Microbes Infect 2000, 2:1041-1050. PubMed Abstract | Publisher Full Text.

[14]. World Health Organization, "Dengue and Dengue haemorrhagic fever," Fact sheet, pp. 117, 1996.

[15]. S. B. Halstead, "Pathogenisis of dengue: challenges to molecular biology," Science, vol. 239, no. 4839, pp. 476-481, 1988.

[16]. S. Balaya, S. D. Paul, L. V. D'Lima, and K. M. Pavri, "Investigations on an outbreak of dengue in Delhi in 1967," Indian Journal of Medical Research, vol. 57, no. 4, pp. 767-774, 1969.

[17]. F.M. Rodrigues,M. R. Patankar, K. Banerjee et al., "Etiology of the 1965 epidemic of febrile illness in Nagpur city, Maharashtra State, India," Bulletin of theWorld Health Organization, vol.46, no. 2, pp. 173-179, 1972.

[18]. V. S. Padbidri, C. N. Dandawate, and M. K. Goverdhan, "Aninvestigation of the aetiology of the 1971 outbreak of febrile illness in Jaipur city, India,” Indian Journal ofMedical Research, vol. 61, no. 12, pp. 1737-1743, 1973.

[19]. P. V. Karamchandani, "Study of 100 cases of dengue fever in Madras Penitentiary," Indian Med Gazette, vol. 72, pp. 532- 534, 1973.

[20]. B. K. Aikat, N. R. Konar, and G. Banerjee, "Haemorrhagic fever in Calcutta area," Indian Journal of Medical Research, vol. 152, pp. 660-675, 1964.

[21]. Ramalingaswami V: Presentations to participants: The changing paradigms of dengue. Dengue outbreak in Delhi: Round table conference series: Ranbaxy Science Foundation; 1996, 7-9.

[22]. Kabra SM, Verma IC, Arora NK, Jain Y, Kabra V: DHF in children in Delhi. Bull WHO 1992, 45:105-108. 
[23]. Anonymous 2014. Annual report of the Directorate of NVBDCP, National Vector Borne Disease Control Programme: http://www.nvbdcp.gov.in/home.htm

[24]. Banik GB, Pal TK, Mondal A, Chakraborty MS, Chakravarty SK. Dengue haemorrhagic fever in Calcutta. Indian Paediatr 1994; 31: 685-687.

[25]. Ghosh SN, Pavri KM, Singh KRP. Investigations on the outbreak of dengue fever in Ajmer City, Rajasthan State in 1969. Part I. Epidemiological, clinical and virological study of the epidemic. Indian J Med Res1974; 62: 511-522.

[26]. Chouhan GS, Rodrigues FM, Shaikh BH et al. Clinical and virological study of dengue fever outbreak in Jalore city, Rajasthan 1985. Indian J Med Res 1990; 91:414-418.

[27]. Seth P, Broor S, Dar L, Sengupta S, Chakraborty M. Dengue outbraeak in Delhi laboratory diagnosis in Dengue Outbreaks in Delhi, P. L. Sarma and O. P. Sood, Eds., pp. 28-30, Ranbaxy Science Foundation, Gurgaon, India, 1996.

[28]. Broor S, Dar L, Sengupta S, Xess I, Seth P. The first major outbreak of dengue hemorrhagic fever in Delhi, India. Emer Infect Dis, 1999; 5: 589-590.

[29]. Cherian T, Ponnuraj E, Kurruvila T, Kirybakaran C, John TJ, Raghupati P. An epidemic of dengue haemorrhagic fever and dengue shock syndrome in and around Vellore. Indian J Med Res 1994; 106:1-3.

[30]. Teixeira MDG, Costa MCN, Guerra Z, Barreto ML: Dengue in Brazil: Situation-2001 and trends. Dengue Bull 2002, 26:70-76.

[31]. Sukri NC, Laras K, Wandra T, Didi S, Larasati RP, Rachdyatmaka JR: Transmission of epidemic dengue hemorrhagic fever in easternmost Indonesia. Am J Trop Med Hyg 2003, 68(5):529-535. PubMed Abstract | Publisher Full Text

[32]. Barrera R, Delgado N, Jimenez M, Valero S: Eco-epidemiological factors associated with hyper endemic dengue hemorrhagic fever in Maracay city, Venezuela.

[33]. Anonymous. Rapid diagnostic test (RDT) for the Detection of Dengue IgM/ IgG Antibodies and NS1 antigen in Human Serum/Plasma" according to the manufacturer's protocol of J. Mitra and Co. Pvt. Ltd; used in 2013.

[34]. Anonymous. Microwell ELISA test for the Detection of Dengue IgM/ IgG Antibodies and NS1 antigen in Human Serum/Plasma according to the manufacturer's protocol of J. Mitra and Co. Pvt. Ltd; used in 2013.

[35]. Lanciotti RS, Calisher CH, Gubler DJ, Chang GJ, Vorndam AV. Rapid detection and typing of dengue viruses from clinical samples by using reverse transcriptase polymerase chain reaction. J Clin Microbiol 1992; 30: 545-551.

[36]. Gubler DJ, Reiter P, Ebi KL, Yap W, Nasci R, Patz J: Climatic variability and change in the United States: Potential impacts on vector and rodent-borne diseases. Environ Health Perspec 2001, 109:223-249.

[37]. Amin MMM, Hussain AMZ, Murshed M, Chowdhury IA, Mannan S, Chowdhuri SA, Banu D: Sero-Diagnosis of dengue infection by haemagglutination inhibition test (HI) in suspected cases in Chittagong, Bangladesh. Dengue Bull 1999, 23:34-38

[38]. Naing CM, Lertmaharit S, Naing KS: Time-series analysis of dengue fever/Dengue hemorrhagic fever in Myanmar since 1991. Dengue Bull 2002, 26:24-32.

[39]. Rebelo JM, Costa JM, Silva FS, Pereira YN, da Silva JM: Distribution of Aedes aegypti and dengue in state of Maranhao, Brazil. Cad-Saude-publica 1999, 15(3):477-486. PubMed Abstract

[40]. Barrera R, Delgado N, Jimenez M, Valero S: Eco-epidemiological factors associated with hyperendemic dengue hemorrhagic fever in Maracay city, Venezuela. Dengue Bull 2002, 26:84-95.

[41]. Strickman D, Kittayapong P: Dengue and its vectors in Thailand: Introduction to the study and seasonal distribution of Aedes Larvae.

VI. Tables

Table 1: Results of blood specimens ( $\mathrm{n}=1980$ ) diagnosis for detection of Dengue.

\begin{tabular}{|c|c|c|c|c|c|c|}
\hline \multirow{3}{*}{$\begin{array}{l}\text { Age Group } \\
\text { (Years) }\end{array}$} & \multirow{3}{*}{ Total BSE } & \multicolumn{5}{|c|}{ Dengue } \\
\hline & & \multicolumn{3}{|c|}{ Diagnosis (Positive) } & \multicolumn{2}{|c|}{ Result } \\
\hline & & RDT & ELISA & PCR & Positive & Negative \\
\hline $0-1$ & 0 & 0 & 0 & 0 & 0 & 0 \\
\hline$>1-5$ & 16 & 1 & 1 & 1 & 1 & 15 \\
\hline$>5-10$ & 49 & 9 & 9 & 8 & 9 & 40 \\
\hline$>10-15$ & 111 & 28 & 28 & 28 & 28 & 83 \\
\hline$>15$ and above & 1804 & 703 & 707 & 696 & 707 & 1097 \\
\hline Total & 1980 & 741 & 745 & 733 & 745 & 1235 \\
\hline
\end{tabular}

BSE: blood samples examined. Prevalence (\%) of dengue: 37.6.

Table 2: Distribution of prevalence of the dengue infection (DI) among different age groups and sex wise in Angul district, Odisha during Jan-Dec, 2013.

\begin{tabular}{|c|c|c|c|c|c|c|c|c|c|}
\hline \multirow{2}{*}{$\begin{array}{l}\text { Age Group } \\
\text { (Years) }\end{array}$} & \multirow{2}{*}{$\begin{array}{l}\text { Total } \\
\text { BSE }\end{array}$} & \multicolumn{2}{|c|}{ Male } & \multicolumn{2}{|c|}{ Female } & \multirow{2}{*}{$\begin{array}{c}\text { Total } \\
\text { positive }\end{array}$} & \multirow{2}{*}{$\begin{array}{c}\text { Case } \\
\text { positivity } \\
\text { rate in } \%\end{array}$} & \multirow[b]{2}{*}{ Deaths } & \multirow{2}{*}{$\begin{array}{c}\text { Case fatality } \\
\text { rate }(\mathrm{CFR}) \text { in \% }\end{array}$} \\
\hline & & BSE & Positive & BSE & Positive & & & & \\
\hline $0-1$ & 0 & 0 & 0 & 0 & 0 & $\mathbf{0}$ & 0.0 & 0 & 0 \\
\hline$>1-5$ & 16 & 10 & 0 & 6 & 1 & 1 & 6.3 & 0 & 0 \\
\hline$>5-10$ & 49 & 27 & 6 & 22 & 3 & 9 & 18.4 & 0 & 0 \\
\hline$>10-15$ & 111 & 68 & 21 & 43 & 7 & 28 & 25.2 & 0 & 0 \\
\hline$>15$ and above & 1804 & 1230 & 518 & 574 & 189 & 707 & 39.2 & 0 & 0 \\
\hline Total & 1980 & 1335 & 545 & 645 & 200 & 745 & 37.6 & 0 & 0 \\
\hline Mean & 396.0 & 267.0 & 109.0 & 129.0 & 40.0 & 149.0 & 17.8 & 0 & 0 \\
\hline
\end{tabular}


Prevalence of dengue viral infection (DI) in and around of Angul district of Odisha, India: ...

Table 3: Distribution of dengue incidence (primary \& secondary) cases by sex \& age group wise in the study area of Angul district, Odisha during Jan-Dec, 2013.

\begin{tabular}{|c|c|c|c|c|c|c|c|c|}
\hline \multirow{2}{*}{$\begin{array}{l}\text { Age Group } \\
\text { (Years) }\end{array}$} & \multirow{2}{*}{$\begin{array}{l}\text { Suspected } \\
\text { cases }\end{array}$} & \multirow{2}{*}{ Positive } & \multicolumn{3}{|c|}{ Dengue Primary cases } & \multicolumn{3}{|c|}{ Dengue Secondary cases } \\
\hline & & & Male & Female & Total & Male & Female & Total \\
\hline $0-1$ & 0 & 0 & 0 & 0 & 0 & 0 & 0 & 0 \\
\hline$>1-5$ & 16 & 1 & 0 & 1 & 1 & 0 & 0 & 0 \\
\hline$>5-10$ & 49 & 9 & 6 & 3 & 9 & 0 & 0 & 0 \\
\hline$>10-15$ & 111 & 28 & 20 & 7 & 27 & 1 & 0 & 1 \\
\hline$>15$ and above & 1804 & 707 & 508 & 170 & 678 & 10 & 19 & 29 \\
\hline Total & 1980 & 745 & 534 & 181 & 715 & 11 & 19 & 30 \\
\hline Mean & 396.0 & 149.0 & 106.8 & 36.2 & 143.0 & 2.2 & 3.8 & 6.0 \\
\hline
\end{tabular}

Table 4: Month wise distributions of prevalence of dengue infection (primary \& secondary) cases in Angul district, Odisha during Jan-Dec, 2013.

\begin{tabular}{lccccc}
\hline Month & Positive & $\begin{array}{c}\text { IgM } \\
\text { (DEN-P) }\end{array}$ & $\begin{array}{c}\text { \% of } \\
\text { DEN-P }\end{array}$ & $\begin{array}{c}\text { IgM+IgG } \\
\text { (DEN-S) }\end{array}$ & $\begin{array}{c}\text { \% of } \\
\text { DEN-S }\end{array}$ \\
\hline July & 27 & 26 & 3.5 & 1 & 0.1 \\
August & 215 & 207 & 27.8 & 8 & 1.1 \\
September & 318 & 305 & 40.9 & 13 & 1.7 \\
October & 166 & 160 & 21.5 & 6 & 0.8 \\
November & 17 & 15 & 2.0 & 2 & 0.3 \\
December & 2 & 2 & 0.3 & 0 & 0.0 \\
$\quad$ Total & $\mathbf{7 4 5}$ & $\mathbf{7 1 5}$ & $\mathbf{9 6 . 0}$ & $\mathbf{3 0}$ & $\mathbf{4 . 0}$ \\
Mean & $\mathbf{6 2 . 1}$ & $\mathbf{5 9 . 6}$ & $\mathbf{8 . 0}$ & $\mathbf{2 . 5}$ & $\mathbf{0 . 3}$ \\
\hline
\end{tabular}

DEN-P = Dengue primary infection, DEN-S = Dengue secondary infection.

From January to June, dengue was prevalent, '0' values were omitted.

Table 5: Climatologically status of Angul district of Odisha, India during Jan.- Dec., 2013).

\begin{tabular}{|c|c|c|c|c|}
\hline Month & \multicolumn{2}{|c|}{ Temperature $\left({ }^{0} \mathrm{C}\right)$} & Relative humidity (\%) & Rain fall (MM) \\
\hline February & 38 & 14 & 67 & 20.8 \\
\hline April & 43 & 29 & 75 & 12.6 \\
\hline May & 46 & 29 & 85 & 90.2 \\
\hline June & 43 & 24 & 75 & 220.4 \\
\hline September & 34 & 21 & 80 & 354.6 \\
\hline October & 32 & 20 & 78 & 70.6 \\
\hline November & 32 & 17 & 64 & 5.4 \\
\hline December & 31 & 14 & 64 & 5.4 \\
\hline Mean & 36.8 & 20.6 & 74.7 & 108.7 \\
\hline
\end{tabular}

\section{Figures}

Figure 1:

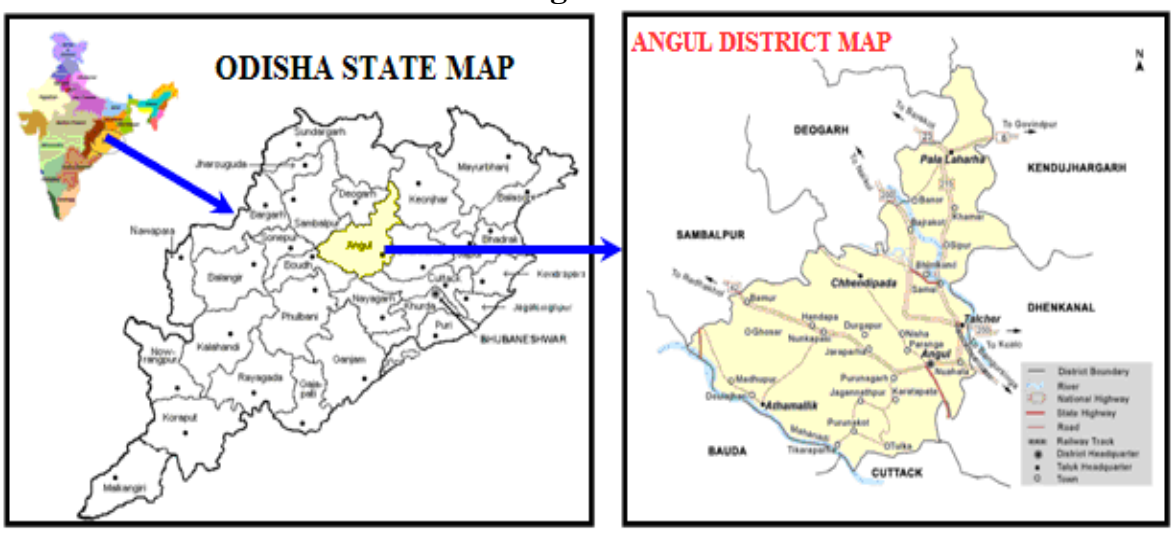

Figure 1: Map showing the study area of Angul district, Odisha. 
Figure 2:

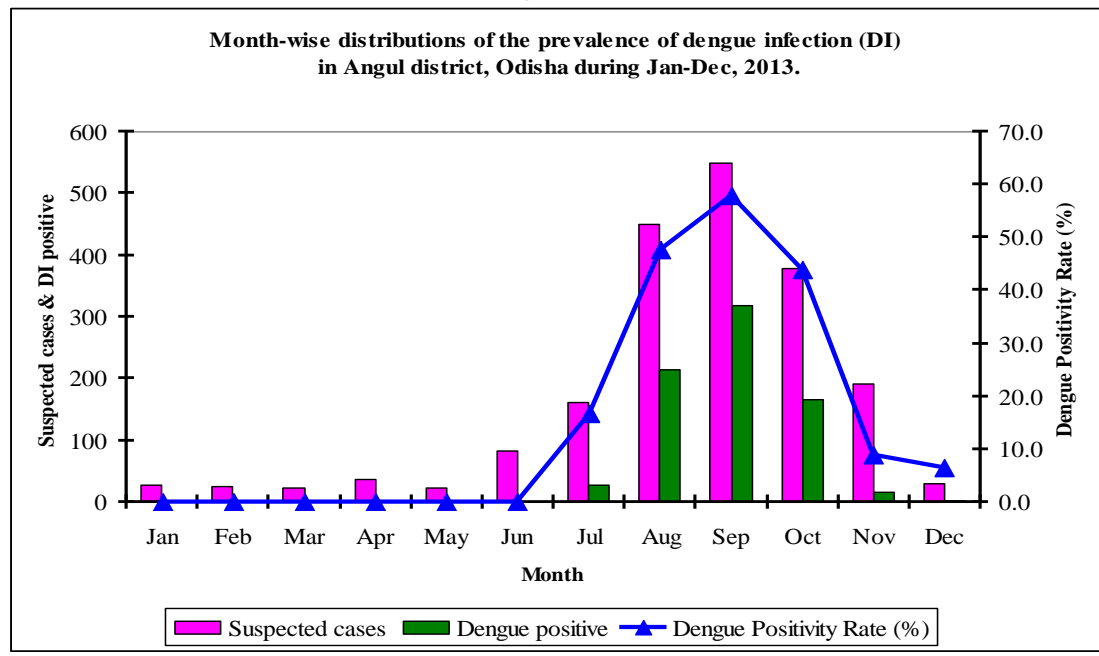

Figure 2:

Month-wise distributions of the prevalence of dengue infection (DI) in Angul district, Odisha during Jan-Dec, 2013

Figure 3:

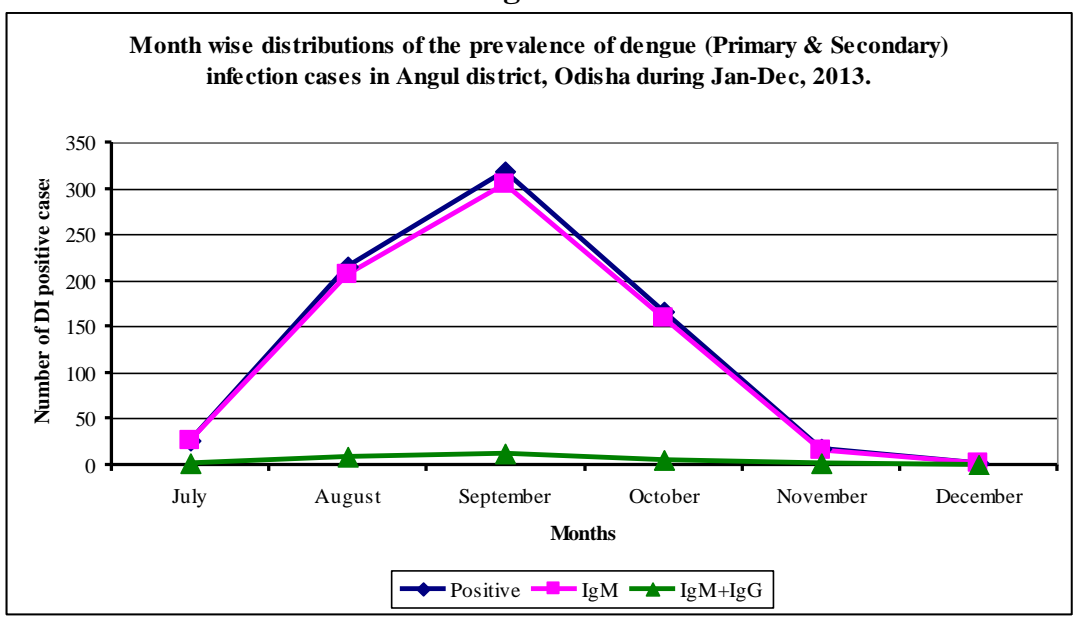

Figure 3: $\quad$ Month wise distributions of the prevalence of dengue infection (primary \& secondary) cases in Angul district, Odisha during Jan-Dec, 2013.

Figure 4:

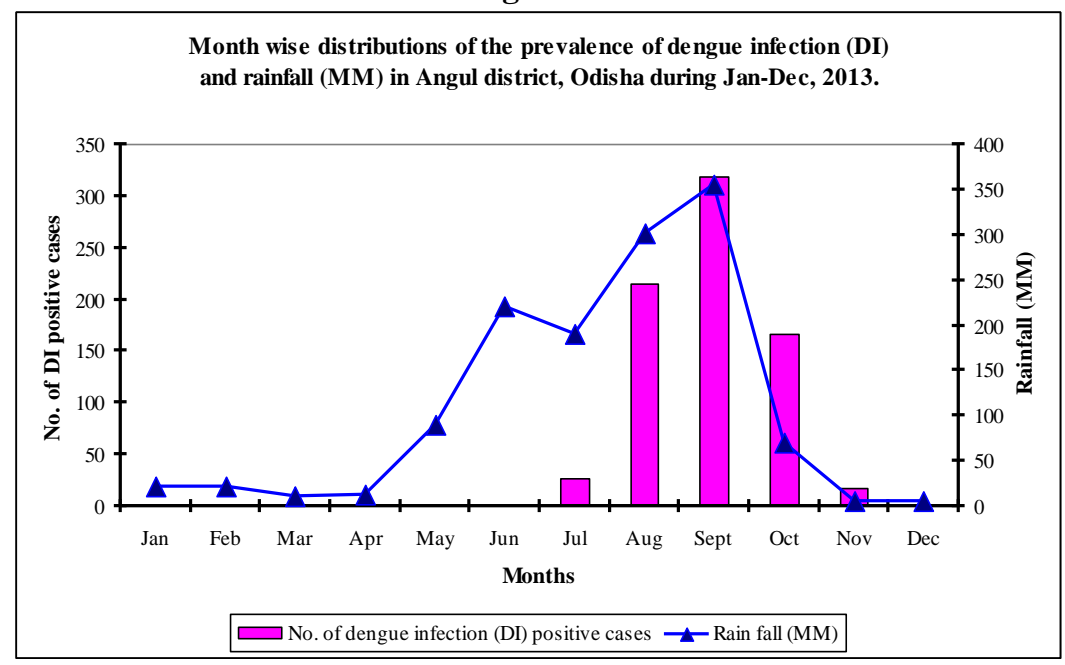

Figure 4: Month wise distributions of the prevalence of dengue infection (DI) and rainfall (MM) in Angul district, Odisha during Jan-Dec, 2013. 
Figure 5:

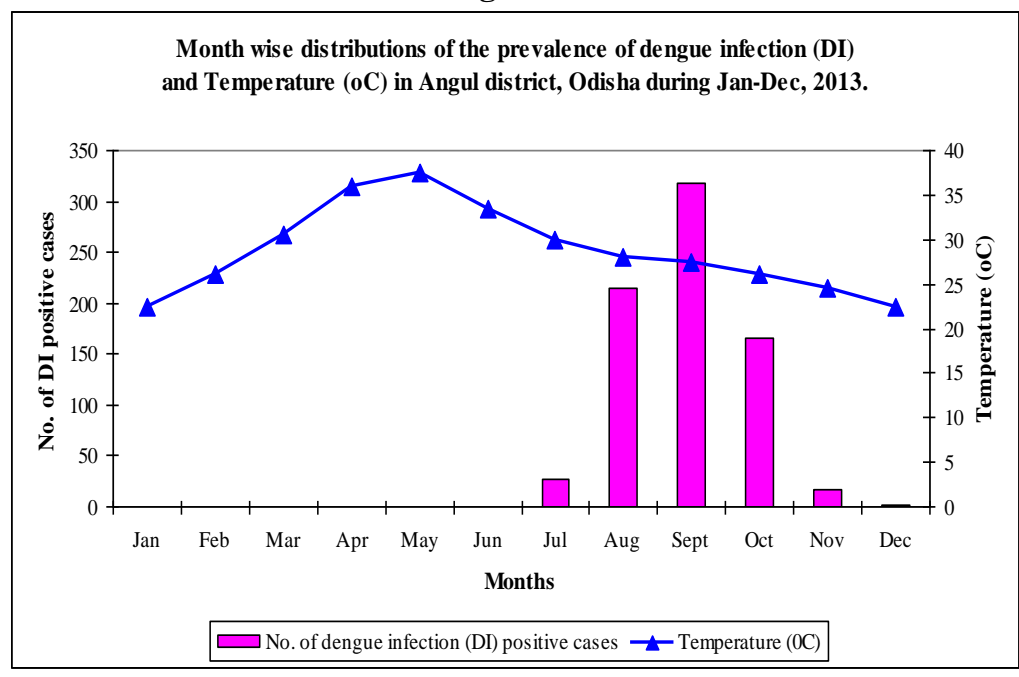

Figure 5: Month wise distributions of the prevalence of dengue infection (DI) and Temperature $\left({ }^{\circ} \mathrm{C}\right)$ in Angul district, Odisha during Jan-Dec, 2013.

Figure 6:

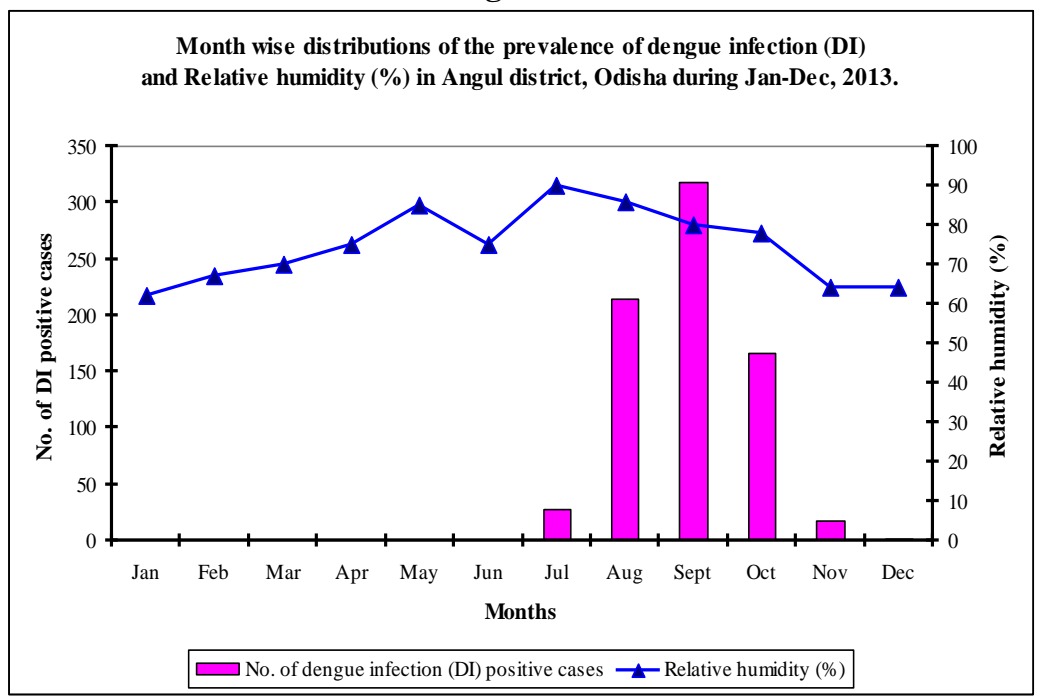

Figure 6: $\quad$ Month wise distributions of the prevalence of dengue infection (DI) and Relative humidity (\%) in Angul district, Odisha during Jan-Dec, 2013. 